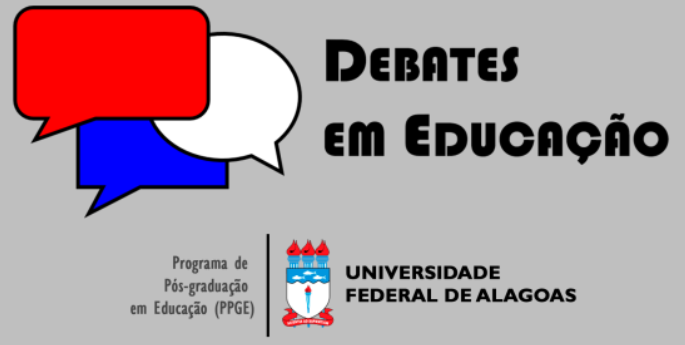

ISSN Eletrônico 2175-6600

Vol. 12 | Número Especial 2 | 2020

\section{Bethânia Bittencourt}

(9) iD

Universidade Federal do Rio de Janeiro (UFRJ) bethania.ufrj@gmail.com

\section{Daniela Patti do Amaral}

9 iD

Universidade Federal do Rio de Janeiro (UFRJ) danielapatti.ufrj@gmail.com

\section{O ORIENTADOR PEDAGÓGICO NA POLÍTICA EDUCACIONAL: DISPUTAS E TENSÕES}

\section{RESUMO}

$\bigcirc$ presente artigo discute a polissemia de termos que podem definir o orientador pedagógico e debate as tensões e disputas sobre este profissional na legislação brasileira. Trata-se de uma pesquisa qualitativa de cunho bibliográfico e documental e, para a análise, utilizamos textos oficiais de redes municipais de educação de municípios da Baixada Fluminense, em diálogo com a Lei de Diretrizes e Bases da Educação (BRASIL, 1996); as Diretrizes Curriculares Nacionais do curso de Pedagogia (BRASIL, 2006); além das tensões e disputas na cena contemporânea. Foram encontrados nos documentos legais aspectos que evidenciam disputas no sentido de estabelecer o trabalho desse profissional da escola, especialmente entre a atuação na docência e como especialista em educação.

Palavras-chave: Política Educacional. Orientador Pedagógico. Gestão Escolar.

\section{THE PEDAGOGICAL ADVISOR'S IN EDUCATIONAL POLICY: DISPUTES AND TENSIONS}

\section{ABSTRACT}

This article discusses the polysemy of terms that may define the pedagogical advisor and debates the tensions and disputes about this professional in the Brazilian legislation. It is a qualitative research, of bibliographic documentary nature and, for the analysis, we used officials documents from municipal education networks at Baixada Fluminense, in dialogue with the Law of Guidelines and Bases of Education (BRAZIL, 1996), national curricular guidelines for Pedagogy course (BRAZIL, 2006) and even tensions and disputes in Brazil contemporary scene. In the legal documents, aspects were found that show disputes in the sense of establishing he work of this school professional, especially between teaching and the work as a specialist in education.

Keywords: Educational Policy; Pedagogical Advisor; School Management.

Submetido em: 04/11/2019

Aceito em: 17/08/2020

Publicado em: 30/12/2020

do http://dx.doi.org//0.28998/2175-6600.2020v I 2nEsp2p60-75 


\section{INTRODUÇÃO}

$\mathrm{Na}$ pluralidade de unidades sub nacionais brasileiras, podemos encontrar diferentes formas de organização da gestão das escolas. Nesse contexto, diversificadas nomenclaturas são definidas para os profissionais de educação que atuam na administração; no planejamento; na inspeção; supervisão e orientação educacional como determina a Lei de Diretrizes e Bases da Educação Nacional (LDB) 9.394 (BRASIL, 1996), tais como: orientador pedagógico; supervisor pedagógico/educacional; coordenador pedagógico. Esta diversificação ocorre pela relativa autonomia que os estados e municípios têm para organizar seus sistemas de educação, de acordo com as suas peculiaridades. Nesse sentido, este artigo tem como objetivos: I) discutir as mudanças na legislação brasileira e as tensões concernentes à hipótese de o orientador pedagógico ser um profissional do magistério e ator da articulação do trabalho pedagógico na escola; 2) debater as diferentes formas como este profissional pode ser identificado pelos sistemas. Pelo próprio volume de sistemas de ensino, é possível observar uma atuação mais ou menos próxima das atividades acima citadas o que pode indicar, inclusive, o perfil deste profissional em cada sistema.

Para o esforço de debruçarmo-nos neste estudo de cunho bibliográfico e documental, optamos pela análise das legislações nacionais (BRASIL, 1996, 2006) e, também, de documentos sobre o contexto do estado do Rio de Janeiro que se referem ao orientador pedagógico de diferentes municípios. O presente trabalho deriva da pesquisa realizada no mestrado em educação no período de 2017 a 2019 , que investigou a atuação dos orientadores pedagógicos através de análise documental e aplicação de questionários em uma rede municipal localizada no estado do Rio de Janeiro (AUTOR, 2019). Assim, a nomenclatura adotada neste artigo refere-se ao termo utilizado na pesquisa na qual este trabalho se originou, o que está diretamente ligado à empiria que serviu como base. Com base na pesquisa de mestrado realizada, debatemos os nomes mais comuns - orientador pedagógico, coordenador pedagógico e professor orientador pedagógico - que aparecem no universo da pesquisa realizada: a Baixada Fluminense', região geopolítica do estado do Rio de Janeiro (AUTOR, 20 I9). Concordamos com Firmino (2017) ao afirmar que, acerca das diversas denominações possíveis sobre esse profissional é preciso estarmos atentos para essas diferenças em cada rede de ensino, seus diferentes contextos e acordos, que podem dizer algo sobre a proposta de educação que cada uma dessas redes tem por definição.

O problema em questão se desenvolve em torno da atuação e do perfil profissional previsto nas políticas educacionais para o orientador pedagógico, considerando a LDB 9.394/ 96, a Resolução do Conselho Pleno do Conselho Nacional de Educação (CNE/ CP) nº 0I/2006 que institui as Diretrizes

\footnotetext{
' Na Baixada Fluminense estão localizados treze municípios do estado do Rio de Janeiro: Belford Roxo, Duque de Caxias, Guapimirim, Itaguaí, Japeri, Magé, Mesquita, Nilópolis, Nova Iguaçu, Paracambi, Queimados, São João de Meriti e Seropédica. Muitos destes municípios foram desmembrados a partir de Duque de Caxias e Nova Iguaçu.
} 
Curriculares Nacionais para o curso de Pedagogia e a ação do Tribunal de Contas do Estado do Rio de Janeiro (TCE-RJ) com relação à acumulação de cargos de servidores públicos, o que incluiu este profissional (TRIBUNAL DE CONTAS DO ESTADO DO RIO DE JANEIRO, 20I8).

Como opção de análise, optamos pela abordagem do ciclo de políticas formulado por Bowe; Ball e Gold (1992) e Ball (1994) enquanto enfoque epistemetodológico (MAINARDES, GANDIN, 2013). Conforme Bowe; Ball e Gold (1994, p. I 53), "essa abordagem permite uma articulação entre a perspectiva metodológica (ciclo de políticas), o referencial teórico específico utilizado na pesquisa e a análise dos dados". Este referencial abrange os contextos da influência; da produção de textos; da prática; dos efeitos e resultados e da estratégia, no que concerne à formulação, à escrita, à encenação; às táticas e às decorrências das políticas. Os contextos não são lineares e sequenciais; podem, inclusive, estar aninhados uns com outros. Essa perspectiva nos fornece a possibilidade de compreender como os documentos orientadores podem ser interpretados e ressignificados. Como afirmam Mainardes e Gandin (20।3), a abordagem do ciclo de políticas explica que as políticas não são meramente implementadas, mas reinterpretadas, recriadas no contexto da prática através de ajustes, adaptações e criações. Para os autores (idem, p. 159), "as políticas estão inseridas em um campo não nivelado, mas em um espaço onde alguns discursos têm uma maior capacidade de figurar nas políticas".

A forma como cada sistema de ensino - estadual ou municipal - nomeia este profissional da gestão escolar está relacionada a como cada uma destas instâncias sub nacionais interpretou as normas legais nacionais, nesse caso, a LDB (BRASIL, 1996) e as Diretrizes Curriculares Nacionais para o curso de Pedagogia (DCN) (BRASIL, 2006) e traduziu para seus textos políticos próprios. Bowie, Ball e Gold ( 1992 ) afirmam que os autores das políticas não possuem controle dos significados dos textos políticos. Podemos considerar que os leitores desses textos e os seus contextos possuem histórias e culturas e diferentes aspectos influenciam a interpretação das políticas. Ademais, as políticas mudam de acordo com as arenas e as interpretações (BALL, 1994).

Há textos políticos mais legíveis e escrevíveis (BOWE, BALL, GOLD, 1992), isto é, com menor e maior possibilidade de reescrita e reinterpretação. Textos políticos podem ser legíveis quando possuem uma baixa possibilidade criativa a partir deles, ou seja, é pouco provável que sejam realizadas reinterpretações e readequações ao contexto para o qual se destina. Isso se deve ao fato de esse tipo de texto estar tão fechado que não permite margem para que outros formuladores derivem outros textos distantes dele. Os textos escrevíveis dão maior possibilidade criativa de interpretá-los e ressignificá-los; servem de base para a formulação de outros textos e outras políticas que dialogam em maior abertura com o espaço local. Permitem, assim, mais autonomia para que estados e municípios se adequem e elaborem políticas e programas que se afinem mais a suas realidades. Um afastamento considerável de uma normativa pode tornar um novo texto uma espécie de infidelidade normativa (LIMA, 20I I), quer 
dizer, uma apropriação local de uma lei como a LDB - que fornece diretrizes gerais para todos os sistemas de ensino - pode se tornar parcialmente ou totalmente descolada do que ela disciplinava.

A maneira como cada município ou estado brasileiro interpretou a atuação, a função ou o cargo, como nomeou quem e quantos são os atores escolares que compõem a gestão escolar vai colocar em cena como cada um deles se apropriou da normativa nacional para o seu contexto local. Além disso, indicam de que forma compreendem o perfil profissional, incorporando questões, culturas e histórias locais.

Podemos encontrar sistemas de ensino que compreendem o orientador pedagógico nas diversas denominações já elencadas, mesmo que existem diferenças na atuação deste profissional de um contexto para o outro. A nomenclatura pode nos dizer se a concepção do perfil de atuação pode ter sido idealizada de forma direcionada a um caráter horizontal, fiscalizador, controlador, mais voltada à ação na escola ou na tentativa de garantia de funcionalidade e controle dos programas e políticas emanadas dos órgãos de nível macro e meso - Ministério da Educação, Conselho Nacional de Educação e Secretarias estaduais ou municipais de educação, respectivamente (RANGEL, 2002; FIRMINO, 20I7; AUTOR, 20I9)-. Além da interpretação na construção do perfil do orientador pedagógico - ou qualquer outra que seja a denominação - os recursos e o contexto de cada estado e município vão determinar, em alguma medida, a condição de compreensão acerca deste profissional, o que nos ratifica o que já fora expresso por Bowe, Ball e Gold ( 1 992) que as políticas não se findam no momento legislativo.

Nesse contexto, acreditamos que este artigo, apesar de suas limitações em apresentar um contexto localizado da análise da política, poderá contribuir para a reflexão das demais redes de ensino e profissionais da educação, sobre a elaboração de textos políticos de seleção de orientadores pedagógicos, bem como seu perfil e atuação na educação básica. Poderá ampliar o arcabouço teórico do assunto e impulsionar outros pesquisadores a reunirem dados locais de diferentes fontes permitindo focos múltiplos. (MAINARDES, GANDIN, 2013).

O artigo está dividido em três partes, além desta introdução, que seguem em direção a discutir a polissemia de termos que podem designar o orientador pedagógico; os percursos sobre a formação e atuação do orientador pedagógico previstos no ordenamento legal analisado; as tensões contemporâneas acerca da atuação como profissional da educação e especialista a partir da ação do Tribunal de Contas do Estado do Rio de Janeiro e, por fim, as considerações finais.

\section{ORIENTADOR PEDAGÓGICO: POLISSEMIA}

A utilização da nomenclatura de orientador pedagógico é opção do estudo que gerou este artigo, contudo, é importante demarcar que não somente essa designação é encontrada nos ordenamentos legais 
das diferentes instâncias sub nacionais (MOEHLECKE, 2017) e na literatura do assunto a que se recorreu para interlocução na produção da dissertação. Assim, considera-se necessário evidenciar os termos utilizados para designar o profissional sujeito desta pesquisa, uma vez que se podem encontrar diversas nomenclaturas para denominá-lo. Tal designação pode ser determinada pela especificidade da sua atuação, pela forma e pelo perfil como cada sistema de ensino concebe esse profissional, dentre outros aspectos.

Outro ponto relevante no debate da forma como os sistemas designam os seus atores escolares tem a ver com a diferença entre o profissional atuar como cargo e como função. Nesse sentido, compreendemos como cargo uma responsabilidade inerente a uma posição profissional, obrigação, atribuições próprias de um determinado profissional que tem em sua natureza a atribuição que lhe é conferida. Partimos da premissa de que a chegada ao cargo de orientador pedagógico pode ocorrer através de concurso público. Nesse caso, o profissional tem a garantia da permanência no cargo, independentemente das mudanças políticas ocorridas no sistema de ensino ou na instância sub nacional para os quais prestou concurso. Consideramos que função remete a uma atividade ou uma prática exercida por um profissional, mas que não é inerente a seu cargo, a sua origem enquanto profissional. Um docente aprovado em um concurso público para o magistério pode vir a ocupar diversas funções - chefia; coordenações; entre outras - por períodos específicos, que poderão - ou não - prever gratificações (AUTOR, 2019).

Rangel (2002) afirma que são utilizadas as designações: supervisão; supervisão educacional; supervisão escolar; supervisão pedagógica; orientação pedagógica; coordenação, coordenação pedagógica; coordenação de área ou de disciplina, havendo algumas diferenças acerca da designação do profissional da orientação pedagógica. Todas essas denominações podem, de forma abrangente, nomear o profissional da escola que articula o trabalho pedagógico desenvolvido - interna ou externamente - numa perspectiva macro ou micro, administrativa ou pedagógica, mas que possuiu a gestão da escola como ponto central do seu trabalho.

A pluralidade de termos representa a complexidade do grande número de sistemas e redes de educação no cenário brasileiro, além dos aspectos sócio historicamente construídos acerca desse profissional. Essa construção no tempo e na diversidade de contextos pode também explicar as ressignificações e recontextualizações da função e da atuação do orientador pedagógico. É possível que outras nomenclaturas possam existir nas muitas redes e sistemas de ensino distribuídas pelos municípios e estados brasileiros, entretanto elencamos aqui as mais comuns na literatura sobre o tema. Nesse aspecto, Moehlecke (2017, p. 226) afirma que:

[...] adentrar essa área implica deparar-se com grande variedade de expressões e nomenclaturas utilizadas ao longo da história da educação no Brasil para designar diferentes funções criadas para a ação junto à gestão das escolas. A própria LDBEN/96 utiliza os termos inspeção, supervisão e orientação educacional para se referir ao profissional da educação que atua nas funções de 
orientação e coordenação pedagógicas, expressões que também ganham contornos locais nas legislações de estados e municípios.

A variedade de nomes para identificar o profissional também pode ser explicada pelo fato de que os municípios passaram a organizar os seus sistemas de ensino ao se tornarem uma instância sub nacional, conforme artigo 21 I da Constituição Federal (CF) (BRASIL, 1988). Isso significa que cada município - além dos estados que eram os únicos entes que gozavam dessa autonomia até esse marco - passou a definir como serão chamados os profissionais que compõem o seu sistema. $\bigcirc$ fato de os sistemas de ensino terem essa autonomia ajuda a explicar, mas não é o único fator que conduz a uma pluralidade de termos acerca desse profissional da escola e de sua gestão. A oscilação do escopo de atuação do orientador pedagógico através das décadas e dos momentos e contextos históricos educacionais também pode explicar como e porque existem tantos nomes para designar o mesmo profissional.

O orientador pedagógico, em linhas gerais, opera na articulação do trabalho pedagógico na escola de forma coletiva, com a função de integrar as ações que são desenvolvidas para a atividade fim da instituição de ensino. Moehlecke (2017a) aponta, nesse sentido, as funções de articulador, coordenador e formador centralizadas no trabalho junto aos docentes e nos processos de gestão, dentro de uma proposta de construção, pela escola, de seu projeto político e pedagógico de maneira coletiva e participativa abrangendo a participação de professores, alunos, pais, funcionários e comunidade. Para Rangel (20।3), a orientação pedagógica propicia a reflexão teórica sobre a prática e as trocas de experiências, a observação e análise de problemas e soluções comuns, debates de estudos sobre a prática pedagógica. Conforme Ferreira (20I I) possui o trabalho de coordenação da prática educativa que visa assegurar os princípios e as finalidades da educação na prática pedagógica.

A figura do coordenador pedagógico advém, no Brasil, do período de redemocratização dos anos de 1980, dentro de relações de poder mais horizontais e descentralizadas (MOEHLECKE, 20 I 7a). Santos (2012) afirma que o surgimento da figura do coordenador pedagógico ocorreu como uma oposição aos especialistas em educação, redimensionando e revitalizando a função supervisora para uma proposta de coletividade do trabalho que pudesse assegurar a qualidade do ensino e a apropriação do saber escolar.

A nomenclatura professor especialista - orientador pedagógico remete à concepção das habilitações da pedagogia, os especialistas, pensadas no período do regime militar, de expressão tecnicista. Neste formato, assume-se proximidade a uma posição de planejamento em que a posição do professor se reduziria à execução do que o orientador planejou e elaborou, sem muito espaço para criação do docente na sua atividade pedagógica. A mescla entre os termos professor, especialista e orientador pode sugerir que, ao mesmo tempo em que se concebe especialista, engendra também um professor, possivelmente na tentativa de minimizar a separação entre o planejamento e a execução, mas sem deslocálo completamente da atuação de condutor do processo. 
A denominação de professor orientador pedagógico aparece indicando uma possível tentativa de horizontalizar as relações na escola, de modo que este profissional seria entendido como um professor que orienta a ação pedagógica de outros professores e, sobretudo, do coletivo docente. Este movimento transparece uma concepção mais horizontalizada da sua atuação na escola, em diálogo com as DCN (BRASIL, 2006) quando estas definiram, como se verá adiante, a docência como a base de formação do pedagogo e, consequentemente, do orientador pedagógico.

Na análise de editais de seleção de profissionais da educação de municípios localizados na Baixada Fluminense, universo da pesquisa que originou o presente artigo, é possível observar a variedade de nomenclatura. A utilização do termo orientador pedagógico foi observada em Mesquita (2007); Nova Iguaçu (2003) e Queimados (1995; 20 I 0). A nomenclatura de coordenador pedagógico está presente nos documentos analisados em Seropédica (2005) e Mesquita (SECRETARIA MUNICIPAL DE EDUCACÃA DE MESQUITA, 20I3). A denominação de professor especialista orientador pedagógico está prevista em Duque de Caxias (SECRETARIA MUNICIPAL DE EDUCAÇÃO DE DUQUE DE CAXIAS, 20I 5) e, ainda, professor orientador pedagógico está presente no edital mais recente do município de Mesquita (20 I 6).

No plano da ação organizacional, temos duas normativas que disciplinam a atuação e a formação do orientador pedagógico: a LDB 9394/96 e a Resolução CNE/ CP n 01 / 2016 . A partir destas propomos a seguir o debate na cena dos últimos 30 anos no que se refere ao orientador pedagógico.

\section{DA LDB 9.394/96 À RESOLUÇÃO CNE/ CP No 0I/06: PERCURSOS E CONTEXTOS SOBRE O PERFIL DO ORIENTADOR PEDAGÓGICO}

As tensões postas ao se pensar a atuação do orientador pedagógico nos aproximam da reflexão sobre a produção dos textos das políticas. A produção de um texto legal, na perspectiva do ciclo de políticas (BOWE, BALL; GOLD, 1992), é um processo de conflito, resistência e lutas representado por movimentos, vozes e grupos que disputam para que seus interesses sejam legitimados no texto da política. No entanto, nem todas as vozes que pleiteiam a escrita do texto legal são consideradas; algumas podem ser mais valorizadas e legitimadas enquanto outras, abafadas (BALL, 1994). Nessa perspectiva, a aprovação das DCN (BRASIL, 2006) não foi um processo livre de embates, assim como não foi o processo de debate e aprovação da LDB dez anos antes, o que também se reverbera em diferentes contextos como as secretarias de educação e as escolas. Diversas agendas de distintas naturezas disputaram a aprovação desses documentos.

No caso da LDB, a proposta da lei educacional percorreu três governos - José Sarney; Fernando Collor de Mello e Fernando Henrique Cardoso - e, conforme Carneiro (20। 5), sua tramitação foi longa, conflitiva, intensa e ambientada em contextos de correlações de forças que eram ora emancipatórias, ora 
paralisantes. Embora a LDB tenha sido reflexo de um momento em que o país se redemocratizava, não significa que não houve resistências, disputas e que o processo de tramitação e aprovação de um novo preceito legal tenha sido livre de tensões. O projeto da lei passou por várias relatorias, vários substitutivos, ziguezagueou da Câmara para o Senado, em um fluxo variado e por movimentações burocráticas. Os espaços decisórios do Congresso estavam balizados em concepções díspares dos atores políticos (CARNEIRO, 20।5). A LDB estabeleceu mudanças na educação brasileira, refletindo os embates postos em cena no período de redemocratização do país iniciado na década anterior. Cury (2008) ratifica que a LDB traduz uma nova realidade nascida de um possível histórico que se realizou e de uma postura transgressora de situações preexistentes, carregadas de caráter não democrático.

Por sua vez, a Resolução CNE/ CP n 0I/2006 que estabelece as diretrizes curriculares para o curso de Pedagogia também passou por disputas desde 1997 até 2004, com composição e recomposição de comissões de especialistas designadas para elaborar as diretrizes. Uma comissão, em 1998, preconizou as sugestões de instituições de ensino e entidades da área ${ }^{2}$ voltadas para uma concepção de docência como base da formação do pedagogo. Uma nova comissão em 2000 apresentou proposta que compreendia duas ênfases de formação: uma voltada para a formação de docência para a educação infantil e gestão educacional e outra ênfase para a docência dos anos iniciais do ensino fundamental e gestão educacional. Os anos posteriores se seguiram entre formulação e reformulação de comissões quando, por fim, o documento das DCN aprovado definiu-se, contemplando a docência; a participação da gestão e a avaliação de sistemas e instituições de ensino em geral; a elaboração; a execução; o acompanhamento de programas e as atividades educativas em contextos escolares e não escolares (CRUZ, 20 I I).

A produção de textos legais é influenciada pelos movimentos, lideranças, vozes e personagens que reivindicam que os seus desejos e lutas sejam traduzidos e expressos na legislação ou através de práticas que podem delinear a produção do texto legal. Na perspectiva do ciclo de políticas (BOWE, BALL; GOLD, 1992), muitas políticas podem iniciar-se no contexto da influência, no entanto, justamente por se tratar de um ciclo, não podem estabelecer uma linearidade entre os contextos em que se encontram aninhadas (MAINARDES e MARCONDES, 2009). Um contexto pode influenciar o outro, uma vez que possui arenas públicas e privadas, característica observada em todos os contextos do ciclo. Nessas arenas, nem todas as agendas e influências são consideradas legítimas e reconhecidas e somente algumas vozes são ouvidas. Daí o desafio posto na análise de políticas, dos textos produzidos e das suas trajetórias. Isso significa que tanto o texto da LDB quanto o da Resolução CNE/CP nº 0I/2006 sofreram várias influências antes e durante a sua tramitação, haja vista que representam o cenário histórico que balizou a sua elaboração e porque os

\footnotetext{
2 Entre as entidades estão: a Associação Nacional pela Formação de Profissionais da Educação (ANFOPE), a Associação Nacional de Pós-Graduação e Pesquisa em Educação (ANPEd) , o Fórum de Diretores de Faculdades de Educação (FORUNDIR), a Associação Nacional de Política e Administração da Educação(ANPAE) e o Centro de Estudos Educação e Sociedade (CEDES).
} 
textos políticos são produtos de múltiplas agendas e influências e carregam consigo as histórias das quais são produtos (BOWE; BALL; GOLD, 1992).

O recorte temporal-legal de definição do lugar e da atuação do orientador pedagógico como especialista e/ou docente, a partir da LDB, passando pela Resolução CNE/ CP nº 0I/2006 até a escrita deste artigo também traz consigo tensões. Sobre o profissional em tela, a LDB n 9.394/96 normatizou a formação dos profissionais da educação nas áreas de administração, planejamento, inspeção, supervisão e orientação determinando, no artigo 64, que:

[...] a formação de profissionais de educação para administração, planejamento, inspeção, supervisão e orientação educacional para a educação básica, será feita em cursos de graduação em pedagogia ou em nível de pós-graduação, a critério da instituição de ensino, garantida, nesta formação, a base comum nacional (BRASIL, 1996).

Entende-se que estes profissionais, atuantes na educação brasileira, serão formados por meio de cursos de graduação de pedagogia ou em nível de pós-graduação para aqueles que não foram formados em pedagogia. Isto posto, temos como escopo dentre estes profissionais da educação aquele que atua no que estaria mais afinado ao que a normativa chama de supervisão educacional, sabendo que coexistem diferentes significações utilizadas para esse profissional, que podem variar de acordo com o contexto. Quando da aprovação da LDB em 1996, o pedagogo teria a sua formação realizada em curso de pedagogia para o magistério da educação infantil, dos anos iniciais do ensino fundamental, das disciplinas pedagógicas do curso Normal de nível médio e, ainda, a possibilidade de uma ou mais de uma dessas habilitações definidas no art. 64 da LDB.

Na esteira da normatização desse profissional, dez anos após a promulgação da LDB, a Resolução CNE/ CP n 0 I/2006 (BRASIL, 2006) instituiu as DCN e alterou a formação do profissional da pedagogia. O documento determinou a constituição de um profissional da pedagogia generalista, extinguindo as habilitações que fragmentavam a formação do pedagogo em várias fatias, em que este deveria optar por uma dessas áreas, formando-se como um especialista na habilitação escolhida. Herança do período do regime militar, em que se promovia uma educação tecnicista e dividia-se o trabalho pedagógico, as habilitações da pedagogia atendiam à polarização dos profissionais que pensavam a educação - os especialistas - e aqueles que meramente a executavam - os professores. Devido a tal fragmentação, as habilitações foram muito criticadas durante a sua existência, pois, além da característica própria que reforçava o especialíssimo, havia a marca da segmentação da atividade escolar, através de uma lógica essencialmente mercadológica (CRUZ, 20II). Carneiro (20I5) aponta que a formação profissional no curso de pedagogia foi-se apequenando, o que prejudicava a escola enquanto organização e aos alunos enquanto sujeitos em formação. A eventual formação profissional remetia aos cursos de pós-graduação, o que esvaziava a graduação em pedagogia de um perfil formador mais amplo. 
Portanto, a formação em pedagogia que abrange a docência e a formação para a gestão da escola no que tange ao planejamento; à execução, à coordenação e à avaliação das atividades educativas escolares e não escolares - parece apontar para um espectro mais abrangente. O pedagogo formado após a aprovação das DCN pode atuar em todas as áreas compreendidas na gestão escolar e em um leque de docência - anos iniciais do ensino fundamental, da educação infantil e do ensino médio, na modalidade Normal. Tal concepção de formação do pedagogo engloba um espaço ampliado de atuação profissional, assim, essa formação para atuação como administrador, supervisor, orientador, professor e no planejamento do trabalho escolar parece indicar um caminho de superação das polarizações que perpetuaram, por muitos anos, no que se refere ao trabalho na escola. Por outro lado, mesmo não sendo mérito do presente trabalho e que pode refletir uma das suas limitações, há de se realizar o seguinte questionamento: de fato houve a passagem da formação em habilitações para uma formação mais completa, que desse conta da formação inicial do pedagogo, ou o pedagogo passou a ser formado em um especialista em generalidades? Teríamos, então, um pedagogo generalista ou um pedagogo de formação genérica?

Como resultado deste processo de mudanças, partindo da LDB e cruzado pela DCN, temos dois cenários que definem quem é o orientador pedagógico nas escolas: um pedagogo formado para atuar desde a docência na sala de aula até a gestão na escola (BRASIL, 2006) e um professor oriundo de qualquer licenciatura que se especializa em cursos de pós-graduação (BRASIL, 2006). No segundo cenário, o profissional teria uma formação inicial de base na docência, dado que provém das licenciaturas em geral.

\section{TENSÕES CONTEMPORÂNEAS ACERCA DO LUGAR DO ORIENTADOR PEDAGÓGICO: ESPECIALISTA, DOCENTE OU DOCENTE- ESPECIALISTA?}

Para ampliarmos o debate sobre a atuação do orientador pedagógico, apresentamos uma questão que mantém diálogo com a reflexão feita até aqui a respeito deste profissional. No segundo semestre de 20 I8, uma ação do Tribunal de Contas do Estado do Rio de Janeiro (TCE-RJ) teve a finalidade de, entre outros objetivos, verificar a legalidade quanto a acumulações de remunerações, tendo como critério o artigo 37 da CF (BRASIL, 1988). Observamos, como efeito e resultado, a divulgação de listagem de servidores públicos dos municípios e do estado do Rio de Janeiro que possuíam vínculos considerados irregulares, o que culminou em exonerações desses servidores, inclusive orientadores pedagógicos de diversas redes de educação do estado. (TRIBUNAL DE CONTAS DO ESTADO DO RIO DE JANEIRO, 2018). 
As irregularidades foram sustentadas pela impossibilidade da acumulação de dois cargos públicos pelo orientador pedagógico, dado que a CF (BRASIL, 1988) estabelece no inciso XVI do artigo 37.

É vedada a acumulação remunerada de cargos públicos, exceto, quando houver compatibilidade de horários, observado em qualquer caso o disposto no inciso Xl:

a) a de dois cargos de professor;

b) a de um cargo de professor com outro, técnico ou cientifico;

c) a de dois cargos ou empregos privativos de profissionais de saúde, com profissões regulamentadas

Nesse caso, o orientador pedagógico foi considerado como cargo técnico e, no caso de possuir mais de uma matrícula nesta categoria, estaria cometendo uma irregularidade. Na leitura do TCE-RJ, o orientador é exclusivamente um especialista não sendo considerado um profissional do magistério. Contudo, devemos levar em consideração o parágrafo $2^{\circ}$ do art. 67 da LDB 9.394/96, incluído pela lei ${ }^{\circ}$ I l.30 I (CAMARA DOS DEPUTADOS, 2006).

Para os efeitos do disposto no $\S 5^{\circ}$ do art. 40 e no $\S 8^{\circ}$ do art. 201 da Constituição Federal, são consideradas funções de magistério as exercidas por professores e especialistas em educação no desempenho de atividades educativas, quando exercidas em estabelecimento de educação básica em seus diversos níveis e modalidades, incluídas, além do exercício da docência, as de direção de unidade escolar e as de coordenação e assessoramento pedagógico (BRASIL, 2006).

A partir desta leitura, ainda que considerados como técnicos, as atividades dos orientadores pedagógicos, desde 2006, são do âmbito da função do magistério, mesmo que não exercidas na docência, quando ocorridas em estabelecimentos da educação básica.

C contexto dos efeitos e resultados, conforme marinardes (2006) indica que as políticas não possuem simplesmente efeitos, mas resultados. Os textos políticos que disciplinaram o lugar do orientador pedagógico podem ter motivado, em alguma medida, a ação do TCE-RJ. Como afirma o autor, a política produz efeitos e consequências que

podem representar mudanças e transformações significativas na política original. $\bigcirc$ autor afirma que, se tomados de modo isolado, os efeitos de uma política específica podem ser limitados, mas quando efeitos gerais do conjunto de políticas de diferentes tipos são considerados, pode-se ter um panorama diferente. Essa é uma questão relevante no caso em tela, tendo em vista os efeitos da ação do TCE na publicação de uma lista que culminou na exoneração de diversos profissionais que, segundo o órgão, estavam acumulando cargos de forma irregular. Nesse aspecto, a partir das ações localizadas no estado do Rio de Janeiro, indagamos se ações semelhantes podem ter ocorrido nas demais instâncias subnacionais, o que pode levar a um cenário nacional que merece futuras investigações.

Pelo viés das DCN, o orientador, como pedagogo, é formado para todas as esferas da gestão escolar e para a docência de específicas etapas da educação básica. Com a inclusão do parágrafo $2^{\circ}$ da lei n | I.30 I/06, a LDB 9.394/96 e as DCN aprovadas em 2006, que dispõem sobre o curso de Pedagogia, passam a dialogar entre si, visto que, antes disso, a LDB previa um orientador formado pelas habilitações, 
o que deixa de acontecer com a aprovação das DCN e a referida lei. Com esse entendimento, não cabe ao orientador pedagógico a classificação exclusiva de profissional técnico da educação, dado o desempenho de suas atividades na escola básica, como função do magistério. Ambas dialogam com a CF de 1988, se esta for interpretada a partir das normatizações postas após a aprovação das DCN em 2006. Caso contrário, corre-se o risco de interpretar o orientador pedagógico unicamente como técnico, o que aparentemente, foi a percepção do TCE-RJ. Destacamos, adicionalmente, que mesmo o orientador pedagógico com graduação nas demais licenciaturas - que não a Pedagogia - também é um docente.

Diante disto, cabe retomar a nomenclatura de professor orientador pedagógico como aparece no edital do município de Mesquita. Esta parece indicar, dentre muitos fatores, a possibilidade de espelhar uma estratégia por parte dos formuladores das políticas, na tentativa de captar orientadores atuantes em outras redes, beneficiando-se, assim, da experiência desses profissionais. A estratégia intercorre ao acrescentar o termo professor ao cargo, de configurando-o do entendimento de cargo técnico e reorganizando-o como docente. Assim, os orientadores pedagógicos que possuem trajetória de atuação em outros sistemas podem assumir a mesma atuação em cargo público em novos contextos, contornado o balizamento dado pela CF, se lida isoladamente e colocando em cena uma apropriação elástica das normas legais. Ainda que não exercia atividade docente, mas como profissional que realiza a coordenação e o assessoramento pedagógico, como função do magistério, tal como orienta a lei no | | . 30 I/06 e tendo a docência como base da sua formação, o orientador pedagógico não careceria da denominação professor orientador pedagógico para dar-lhe uma roupagem de função do magistério.

Nesse movimento, toma relevo destacar que, apesar de não exercer função docente, o professor orientador, quando assim denominado, é recrutado por meio do concurso com base no piso nacional para o magistério. Nessa esteira, essa denominação pode gerar efeitos e resultados da política quanto à atuação, remuneração e valorização do cargo, uma vez que o orientador sendo designado como professor cera___ 2 enquadrado na categoria docente. Ainda que tenha a sua formação com base na docência, esvaziam-se as possibilidades de pensá-ló como categoria. Em outras palavras, minimizam-se as diferenças de hierarquia, subordinação e fragmentação e maximiza-se um possível cenário de desvalorização. Na Baixada Fluminense, este gesto pode ser percebido nos últimos anos na rede municipal de educação de Mesquita (MESQUITA, 2016) que realizou um concurso público específico para o cargo de professor orientador pedagógico.

No sentido da presente discussão, observamos as diferentes nuances matizadas nos últimos vinte anos, no que concerne ao lugar do orientador pedagógico: de um especialista habilitado em atividades de planejamento e supervisão da escola básica a um docente certificado para atuar em todas as áreas da gestão da escola, isto é, um professor e também gestor, generalizadamente. Todos os balizamentos legais não se afastam, em alguma medida, da docência, já que a formação perpassa pelo curso de pedagogia e 
licenciatura, o que fica ratificado em 2006. Concordamos com o entendimento da lei $n^{\circ}$ | I .301/2006 (BRASIL, 2006), que o orientador pedagógico - embora não atue especificamente na sala de aula, mas na articulação do processo pedagógico e com uma formação ancorada na docência - é um profissional do magistério. Esse debate está situado em um campo de tensões, afınal, a Pedagogia é a única licenciatura que forma, também, especialistas, apresentando uma característica híbrida. Nesse aspecto, estão em foco as finalidades do curso de Pedagogia; o perfil dos egressos e as disputas entre grupos que defendem a concepção da pedagogia como Ciência da Educação, formadora do "pedagogo stricto sensu" (LIBÂNEO, 2002, p. 39) e entre os que defendem o curso como um espaço formador de docentes.

\section{CONSIDERAÇÕES FINAIS}

Neste estudo, propusemos o debate acerca do lugar e da atuação do orientador pedagógico à luz dos textos oficiais que o balizaram e tendo como marco inicial a LDB 9.394/96 e as Diretrizes Curriculares Nacionais para curso de Pedagogia (BRASIL, 2006). As diferentes denominações para o orientador pedagógico indicam que estados e municípios podem fazer interpretações para os textos políticos de seus sistemas de ensino o que, na pluralidade de instâncias subnacionais, gera uma polissemia para o profissional em questão, assim como pode dar pistas de como é pensado seu perfil para cada um desses espaços. $\bigcirc$ termo explorado, dentro do conjunto de diversos nomes que podem ser identificados, é orientador pedagógico devido à empiria que sustentou a pesquisa original da qual se derivou o presente trabalho.

No intento de compreender o orientador pedagógico, analisamos textos políticos para entendermos o movimento de definição deste profissional nos documentos vigentes. Estes escritos oficiais o tratam inicialmente como especialista, e, posteriormente como docente, inclusive. Tal movimento gera efeitos como a ação do TCE-RJ que, em 2018, teve uma interpretação de orientador pedagógico especificamente como especialista e, ainda, os sistemas de ensino que aderem ao termo professor orientador pedagógico promovendo apropriações elásticas das nomenclaturas de modo a estabelecer estratégias para seus textos políticos, em especial, editais de concursos públicos.

Na compreensão da política como ciclo, em que diferentes arenas e sujeitos disputam cada contexto, desde a elaboração até os efeitos e resultados, é possível analisar como, através das lentes específicas de cada um desses contextos, os sujeitos, grupos e instituições vão expressar as suas interpretações, interesses e posições. Nessa perspectiva cíclica, percebe-se a dificuldade de consenso sobre a formação, atuação e lugar do orientador pedagógico, diante da autonomia que possuem as unidades sub nacionais - estados e munícipios para defini-lo. Se, por um lado, os municípios e estados têm autonomia para definir o perfil desse profissional, por outro, o profissional pode ser interpretado como docente, especialista ou uma mescla desses dois perfis. 
Acreditamos que o orientador pedagógico, profissional da educação, atuante na gestão da escola - e que, por formação, tem a possibilidade de atuar em todas as esferas da gestão - também tem a sua atuação definida como função do magistério, uma vez que atua nas atividades que organizam, articulam e promovem o trabalho pedagógico na escola.

\section{REFERÊNCIAS}

BALL, S. Education Reform. What is Policy? Texts, trajectories and toolboxes Open University Press. USA, 1994.

BOWE, R.; BALL, S.; GOLD, A. Reforming education and changing schools. Cases studies in policy sociology. The police process and the processes of policy. London: Routledge, 1992.

BRASIL. Constituição da República Federativa do Brasil de 1988. Disponível em http://www.planalto.gov.br/ccivil_03/constituicao/constituicao.htm. Acesso em ago. 2017.

BRASIL. Lei 9394 de 20 de dezembro de 1996. Estabelece as diretrizes e bases da educação nacional. Disponivel em: http://www.planalto.gov.br/ccivil 03/leis/L9394.htm . Acesso em mar. 2018.

BRASIL. Resolução CNE/CP Nº 0 I de 15 de maio de 2006. Institui Diretrizes Curriculares Nacionais para o Curso de Graduação em Pedagogia, licenciatura. Disponível em:

http://portal.mec.gov.br/cne/arquivos/pdf/rcp0 I_06.pdf. Acesso em mar. 2018.

CAMARA DOS DEPUTADOS. Lei $n^{\circ} 11.301$ de 10 de maio de 2006. Altera o art. 67 da Lei n 9.394, de 20 de dezembro de 1996, incluindo, para os efeitos do disposto no $\S 5^{\circ}$ do art. 40 e no $\S 8^{\circ}$ do art. 201 da Constituição Federal, definição de funções de magistério. Disponível em: http://www2.camara.leg.br/legin/fed/lei/2006/lei- I I30 I - I0-maio-2006-542 I 40-publicacaooriginal49556-pl.html. Acesso em: nov. 2018.

CARNEIRO, M. A. LDB Fácil. Leitura critico-compreensiva artigo a artigo. Petrópolis: Vozes, 2015.

CURY, C. R. A educação básica como direito. Cadernos de Pesquisa. v. 38, n. 134, p. 293-303, 2008.

CRUZ, G. B. Curso de Pedagogia no Brasil. História e Formação com Pedagogos Primordiais. Rio de Janeiro: Wak Editora, 201 I.

FIRMINO, D. L. F. A experiência da coordenação pedagógica em Niterói (RJ). In: MOEHLECKE, S.; AMARAL, D. P.; FERNÁNDEZ, S. J. (Orgs.). História, políticas e experiências de gestão escolar: o lugar da orientação pedagógica nos sistemas de ensino do Rio de Janeiro. Curitiba: Editora CRV, 20 I7. p. 167-180.

FERREIRA, N. S. C. Supervisão educacional: novas exigências, novos conceitos, novos significados. In: Supervisão pedagógica. Princípios e práticas. RANGEL, M. (Org.). Papirus, Campinas, 20 I I, p. 81 - 102.

LIMA, L. Administração escolar: estudos. Porto: Porto Editora, 201 I . p. I68- I7I.

MAINARDES, J. Abordagem do ciclo de políticas: uma contribuição para a análise de políticas educacionais. Educação \& Sociedade, Campinas, vol. 27, n. 94, p. 47-69. 2006. 
MAINARDES, J.; MARCONDES, M. I. Entrevista com Stephen J. Ball: um diálogo sobre justiça social, pesquisa e política educacional. Educação \& Sociedade, Campinas, v. 30, n. I 06, p. 303-319, 2009.

MAINARDES, J.; GANDIN, L.A. A abordagem do ciclo de políticas como epistemetodologia: usos no Brasil e contribuições para a pesquisa sobre políticas educacionais. In: TELLO, C.; ALMEIDA, M.L.P. Estudos epistemológicos no campo da pesquisa em política educacional. Capinas, SP: Mercado das Letras, 2013.

MESQUITA. Edital de concurso público n. 01/2007. Disponível em:

https://www.pciconcursos.com.br/concurso/prefeitura-de-mesquita-rj-4l0-vagas. Acesso em jun. 2019.

MESQUITA. Edital de concurso público n. 01/2016. Disponível em:

http://www.trancabrc.com.br/funrio/Mesquita20 I6/Educacao/arquivos/edital/edital.pdf. Acesso em jun. 2019.

MOEHLECKE, S. O coordenador pedagógico nos sistemas de ensino do Rio de Janeiro: uma nova aposta na gestão das escolas? RBPAE - v. 33, n. I, p. 223 - 239, 2017.

MOEHLECKE, S. A Orientação Pedagógica na gestão escolar no Brasil: história e debates atuais. In: MOEHLECKE, S.; AMARAL, D. P.; FERNÁNDEZ, S. J. (Orgs). História, políticas e experiências de gestão escolar: o lugar da orientação pedagógica nos sistemas de ensino públicos do Rio de Janeiro. CRV Editora, Curitiba, 2017a. p. 17-40.

NOVA IGUAC,U. Lei n 3.526 de 19 de setembro de 2003. Revisa e atualiza o Estatuto do Magistério Público Municipal, de acordo com a Lei 2.905, de 26 de junho de 1998 e dá outras providencias. Disponivel em: http://cmni.rj.gov.br/legislacao/leis_mun/lei_3526.pdf. Acesso em jun. 2018.

QUEIMADOS. Lei n 169 de 17 de fevereiro de 1995. Estabelece o Estatuto do Magistério Público Municipal de Queimados. Disponivel em: http://www.queimados.rj.gov.br/leis.asp.. Acesso em mar. 2018.

QUEIMADOS. Lei $n^{\circ} 1019 / 10$ de 30 de dezembro de 2010. Cria cargos de provimento por concurso público na estrutura organizacional da Secretaria Municipal de Educação - SEMED e dá outras providencias. Disponivel em: http://www.queimados.rj.gov.br/leis.asp. Acesso em mar. 2018.

RANGEL, M. Supervisão: do sonho à ação - uma prática em transformaçãa. In: Fَ FERREIRA, N. S. C.(org.) Supervisão educacional para uma escola de qualidade: da formação à ação. São Paulo: Cortez, 2002. p. 69-96.

RANGEL, M. Consideraç̃̃es sobre o papel do supervisor, como especialista em educação, na América Latina. In: SILVA JR. C. A.; RANGEL. M. Nove olhares sobre a supervisão. Campinas: Papirus, 20।3. p. 147-162.

SANTOS, M. C. G.; SALES, M. P. Gestão democrática da escola e gestão do ensino: a contribuição docente à construção da autonomia na escola. Revista Ensaio. Belo Horizonte, v. |4, n. 02, p. |7| - | 83, 2012 .

SECRETARIA MUNICIPAL DE EDUCAÇÃO DE DUQUE DE CAXIAS. Edital de concurso n. 0I/ 20I5. Disponível em: https://d3du0p87blxrg0.cloudfront.net/concursos/430/60_270720 I5I45326.pdf. Acesso em jun. 2019. 
SECRETARIA MUNICIPAL DE EDUCACÃO DE MESQUITA. Edital nº 010/2013. Processo seletivo interno simplificado para ocupar função de professor coordenador pedagógico nas unidades escolares da rede municipal de Mesquita. Disponivel em: http://www.mesquita.rj.gov.br/pmm/wpcontent/uploads/20 I7/06/EDITAL-SEMED- N\%C2\%BA-0 I 0-20 I3-SEMED-PCP2.pdf. Acesso em jun. 2018.

SEROPÉDICA. Lei n 316 de 14 de dezembro de 2005. Dispõe sobre o plano de carreiras e remuneração dos profissionais da educação no municipio de Seropédica. Disponivel em :

http://seropedica.ri.gov.br/sistema leis/admin/uploads_pdf/lei-316-2005.pdf. Acesso em: jun. 20 I 8.

TRIBUNAL DE CONTAS DO ESTADO DO RIO DE JANEIRO - TCE. Processo n 105.852-6/20I7. Verificar a legalidade da folha de pagamento no que concerne especificamente à acumulação de remuneraçôes e/ ou proventos, bem como a eventuais pagamentos atribuídos a servidores já falecidos. Disponivel em: http://consulta.tce.rj.gov.br/consultaprocesso/PesquisaTextual/Details?numero $=105852 \&$ digito $=6 \&$ ano $=2017$. Acesso em: ago. 2018 .

\section{COMO CITAR ESSE ARTIGO}

\section{Associação Brasileira de Normas Técnicas (ABNT)}

BITTENCOURT, Bethânia; AMARAL, Daniela Patti do. O orientador pedagógico na política educacional: disputas e tensões. Debates em Educação, Maceió, v. 12, p. 60-75, dez. 2020. ISSN 2175-6600.

Disponível em: https://www.seer.ufal.br/index.php/debateseducacao/article/view/8987. Acesso em: dd mmm. aaaa.

\section{American Psychological Association (APA)}

Bittencourt, B., \& Amaral, D. (2020). O orientador pedagógico na política educacional: disputas e tensões. Debates em Educação, I2(Esp2), 60-75. doi: https://doi.org/l0.28998/21756600.2020v12nEsp2p60-75 